\title{
COMPLEMENTARIDADE OU DEPENDÊNCIA? O DILEMA DA ARMÊNIA PÓS-SOVIÉTICA
}

\author{
COMPLEMENTARITY OR DEPENDENCE? THE DILEMMA OF THE POST-SOVIET \\ ARMENIA
}

\author{
Rodrigo Monteiro de Carvalho ${ }^{1}$
}

\begin{abstract}
Resumo
Desde sua independência, em 1991, a Armênia vem buscando adotar uma política externa multivetorial, autointitulada como "política de complementaridade". Esta abordagem foi adotada com o propósito de assegurar diplomaticamente os recursos financeiros e de segurança necessários que a pequena república sul-caucasiana não poderia prover autonomamente. Na prática, no entanto, o que se viu foi uma aproximação política, militar e econômica com a Rússia que, ao longo dos anos, passou a se configurar como uma relação de dependência. O conflito armado contra o Azerbaijão pelo controle da região de Nagorno-Karabakh, que já se estende por três décadas, e o embargo promovido pela Turquia são fatores que agravam o quadro de isolamento da Armênia e a impele a buscar por ajuda externa. O presente artigo pretende discutir os desdobramentos e a viabilidade atual da "política de complementaridade" a partir de análise histórica e documental e da comparação das trajetórias das relações da Armênia pós-soviética com a Rússia, com o Ocidente e com as potências regionais circundantes, Turquia e Irã. Espera-se demonstrar que os graves desafios à segurança nacional limitaram a capacidade do país de conduzir uma política externa independente e que a simples substituição de sua classe dirigente continua sendo insuficiente para alterar o rumo de seus alinhamentos externos e de seu ainda incompleto processo de integração regional.
\end{abstract}

Palavras-Chave: Armênia; Complementariedade; Dependência; Política Externa Multivetorial.

\begin{abstract}
Since its independence in 1991, Armenia has sought to pursue a multi-sectoral foreign policy, self-described as the "complementarity policy". This approach was adopted in order to diplomatically obtain the necessary financial and security resources that the small South Caucasian republic could not provide autonomously. In practice, however, there was a political, military and economic rapprochement with Russia, which over the years has become a relationship of dependency. The three-decade-old armed conflict against Azerbaijan over the control of Nagorno-Karabakh region and Turkey's embargo are factors that worsen Armenia's isolation and impel it to seek foreign aid. This article aims to discuss the developments and the current viability of the "policy of complementarity" based on a historical and documentary analysis and the comparison between the trajectories of post-Soviet Armenian relations with Russia, the West and the surrounding regional powers, Turkey and Iran. It is expected to demonstrate that the serious challenges to national security have limited the country's ability to conduct an independent foreign policy. Furthermore, the mere replacement of its ruling class ought to be insufficient to change the course of its external alignments and its still incomplete process of regional integration.
\end{abstract}

Keywords: Armenia; Complementarity; Dependency; Multi-Vector Foreign Policy.

1 Doutorando em Estudos Contemporâneos pela Universidade de Coimbra. E-mail: rodrigomonteirodecarvalho@gmail.com. ORCID: https://orcid.org/0000-0002-0263-7692. 


\section{INTRODUÇÃO}

O alinhamento externo de um Estado é orientado essencialmente para contrabalançar as ameaças percebidas por ele. Este é o argumento central da teoria de "balança de ameaças", apresentada por Stephen Walt em sua obra "The origins of alliances" (1990) e que serve como base para este presente trabalho, desenvolvido como parte de uma pesquisa mais ampla acerca da construção de alianças militares e do direcionamento das políticas externas das recémindependentes repúblicas do Cáucaso do Sul e dos Balcãs. Este artigo, porém, tem na República da Armênia seu principal objeto de análise. Pretende-se demonstrar que a orientação da política externa armênia a partir de sua independência, em 1991, esteve sempre condicionada pelos graves desafios a sua segurança nacional que limitam a capacidade do país de conduzir uma diplomacia independente e que, em sua busca por aliados, teve a Rússia como sua única opção de parceria viável.

Desde que se emancipou da União das Repúblicas Soviéticas (URSS), a Armênia emprega esforços contínuos para garantir a segurança e a viabilidade econômica do Estado. Alguns elementos adicionam complexidade a estes esforços, tais como (1) a matriz de exportações que se mostra pouco competitiva e com baixa inserção nos mercados internacionais, (2) a escassez de recursos energéticos próprios, aumentando sua dependência da Rússia, e (3) posição geográfica do país afastada dos grandes centros consumidores e sem acesso ao mar. Somam-se a estes entraves duas ameaças perenes à segurança nacional armênia: o embargo econômico imposto pela Turquia e pelo Azerbaijão, que se estende por mais de duas décadas, e o conflito na região de Nagorno-Karabakh, oficialmente paralisado por um cessar-fogo em 1994, mas que demanda constante mobilização de tropas e recursos.

Diante destes desafios, a Armênia adotou, ao menos em discurso, uma política externa multivetorial, ou seja, que preconiza estabelecer relações de cooperação com diferentes e variados países. No caso específico da Armênia, o caráter multivetorial de sua política externa resultou na tentativa de se forjar cooperações mesmo com Estados que se antagonizam entre si, como o Irã e os Estados Unidos. A busca por diversificação, que no discurso oficial ganhou a alcunha de "política de complementaridade", vem norteando seu engajamento internacional desde o período pós-independência. Esta abordagem foi implementada com o propósito de assegurar diplomaticamente os recursos financeiros e de segurança necessários que a pequena república sul-caucasiana não poderia prover autonomamente. Não obstante, em direção contrária, observase ao longo dos anos um movimento persistente de aprofundamento da relação de dependência econômica e estratégica da Armênia perante a Rússia, em detrimento da diversificação idealizada. 
De acordo com Bueno de Mesquita (2009, p.3), o alinhamento externo não é função de um só fator. Elementos como o peso do passado, interesses econômicos das elites, ideologia e autopreservação dos dirigentes influenciam diretamente a orientação da política externa de um Estado. Não obstante, para Kenneth Waltz, “...na anarquia, a segurança é o maior fim. Somente com sua segurança garantida podem os Estados perseguir outros objetivos como tranquilidade, lucro e poder" (WALTZ, 1979, p. 126, tradução livre²). Desta forma, considera-se para esta pesquisa o princípio da segurança nacional como um imperativo decisório da política externa de qualquer Estado. A partir desta premissa, busca-se demonstrar que entre a escolha pelo caminho da complementaridade e o da dependência, resta à Armênia a opção por este último. Por conseguinte, a ascensão ao poder de diferentes grupos políticos domésticos não se faz suficiente para alterar este cenário. Procura-se justificar essas afirmações a partir de uma análise histórica e documental das relações exteriores da Armênia pós-soviética e da comparação entre as trajetórias de suas relações com a Rússia, com o Ocidente e com as potências regionais circundantes, Turquia e Irã. A escolha por esses atores se explica por serem os únicos com ativa ou potencial presença militar na região e, portanto, fontes de ameaça plausíveis. Busca-se identificar o grau e a origem destas possíveis ameaças percebidas pela Armênia de modo que se faça possível a compreensão das suas escolhas de alinhamento externo. O trabalho está dividido em seções que apresentam o desenvolvimento de cada uma destas relações e dos níveis de ameaça percebidos pela Armênia. Por fim, são apresentadas considerações acerca dos achados e expostas as conclusões finais.

\section{RELAÇÕES COM A RÚSSIA}

Desde o estabelecimento das relações diplomáticas entre os dois países, em 1992, mais de 200 acordos e protocolos bilaterais em diversas áreas foram assinados entre as partes. Dentre eles, destaca-se o tratado que regulamenta o estabelecimento de bases militares russas em solo armênio firmado em 1995 e expandido em 2010; e o Tratado de Amizade, Cooperação e Assistência Mútua, firmado em 1997 e expandido em 2001, que abrange aspectos de cooperação política, econômica e militar, incluindo uma cláusula de ajuda recíproca em caso de ataque externo. A Armênia também é assídua signatária dos projetos multilaterais promovidos pela Rússia. Em 1991 foi o único país recém independente do Cáucaso do Sul a assinar a Declaração de Alma-Ata, que formalizou a criação da Comunidade dos Estados Independentes (CEI). Também aderiu, em 1992, ao Tratado de Segurança Coletiva no escopo da CEI. Em 2002, passou a ser membro

\footnotetext{
2 "In anarchy, security is the highest end. Only if survival is assured can states safely seek such other goal as tranquility, profit and power." (WALTZ, 1979, p. 126).
} 
fundador da Organização do Tratado de Segurança Coletivo (OTSC), que substituiu o tratado de segurança anterior. Por fim, em 2015, aderiu à União Econômica Euroasiática (UEE).

Se durante o mandato de Levon Ter-Petrosian, líder do movimento independentista e primeiro presidente armênio (1991-1998), a cooperação entre os dois países foi aprofundada em seu aspecto militar, a partir do termo de Robert Kocharian (1998-2008) foram também estreitados os laços de dependência econômicos e energéticos. Em 2002, em troca do perdão de uma dívida de 93.7 milhões de dólares, a Armênia transferiu ao controle de empresas russas cinco indústrias estatais, incluindo sua principal usina de energia elétrica. Em 2003, mais cinco usinas hidroelétricas passaram ao controle da empresa russa Inter RAO, além dos direitos de operação da usina nuclear de Metsamor. A empresa russa Gazprom exerce o monopólio da distribuição de gás ao ponto de impor a redução do diâmetro do gasoduto que liga o Irã à Armênia de modo a limitar a importação de gás iraniano e a potencial futura exportação para os mercados europeus. Empresas russas também têm garantido o controle total ou parcial dos segmentos de telecomunicações, ferrovias, metalurgia e sistema. Os vínculos econômicos com a Rússia foram aprofundados quando, em 2013, já sob o mandato de Serj Sargsyan (2008-2018), a Armênia abandonou o Acordo de Associação com a União Europeia a fim de aderir à União Euroasiática. O pronunciamento sobre esta decisão aconteceu logo após um encontro entre Sargsyan e o Presidente russo Vladimir Putin ter ocorrido em Moscou, em setembro de 2013. Esse encontro, que fora convocado por Putin, aconteceu pouco depois do anúncio da finalização do documento da associação entre a Armênia e a União Europeia. No entanto, este estado de dependência pode ser compreendido pela posição de isolamento da Armênia, que convive há mais de duas décadas com o embargo econômico imposto pela Turquia e o Azerbaijão e a decorrente não inclusão do país nos projetos de cooperação energética regionais. Os interesses econômicos da elite política armênia, intrinsecamente vinculados aos da Rússia, também devem ser levados em consideração (SAMMUT, 2015, p. 49). Nesse cenário, não causa estranhamento que apenas um partido, dos então seis representados no Parlamento armênio, tenha votado contra a adesão à União Euroasiática (GARFALI et al., 2016, p. 12).

A ambivalência da Rússia no tratamento dado à Armênia e ao Azerbaijão é a razão da maior apreensão entre os dirigentes armênios. Esta preocupação está exposta na Estratégia de Segurança Nacional da República da Armênia que considera o "enfraquecimento ou ineficiência das alianças estratégicas" como uma das principais ameaças externas à segurança nacional. A redação estipula que "a filiação em uma aliança estratégica exige que todos os membros da aliança sejam inerentemente proibidos de adotar qualquer ação que viole os interesses dos outros 
membros da aliança" (NATIONAL SECURITY STRATEGY, 2007, tradução livre ${ }^{3}$ ). A apreensão com a mudança de postura russa coincide com a chegada de Putin à presidência em 2000 e a maior ênfase dada por ele à reaproximação com o governo azerbaijano. Essa reaproximação visava tanto conter a expansão da influência do Ocidente no Cáucaso do Sul, como garantir os interesses econômicos russos na exploração dos recursos minerais da bacia do Mar Cáspio (MIRZOYAN, 2010, p.43). O Conceito de Política Externa da Federação Russa, promulgado em 2000, aponta que:

\begin{abstract}
Séria ênfase será dada ao desenvolvimento da cooperação econômica, incluindo a criação de uma zona de livre comércio e implementação de programas de uso racional comum dos recursos naturais. Especificamente, a Rússia irá trabalhar para a elaboração de um estatuto do Mar Cáspio que permita que os Estados litorâneos possuam uma cooperação mutuamente vantajosa no uso de recursos da região de forma justa e tendo em conta os legítimos interesses de cada um. (THE FOREIGN POLICY, 2000, tradução livre ${ }^{4}$ )
\end{abstract}

Neste contexto, a abrupta adesão da Armênia à União Euroasiática também está associada ao temor de que a aproximação da Rússia com o Azerbaijão pudesse vir a resultar em uma troca condicionada da adesão de Baku à união econômica pelo apoio de Moscou na questão de Nagorno-Karabakh (GARFALI et al., 2016, p. 11). Ainda assim, a adesão armênia à UEE não impediu que a Rússia continuasse com o fornecimento de armamentos avançados para o Azerbaijão, que em 2014 somava $85 \%$ de todas as importações de armas realizadas pelos azerbaijanos (KUCERA, 2015).

O temor de que Moscou troque de lado se justifica. Todo o aparato de defesa da Armênia se apoia na cooperação militar com a Rússia. A Carta da OTSC e o Tratado de 1997 versam sobre a garantia de defesa mútua entre seus membros e são os principais garantidores da segurança nacional Armênia. Somam-se a presença em solo armênio de duas bases militares russas que, em 2010, tiveram suas permissões estendidas por mais 34 anos; o patrulhamento conjunto das fronteiras com Irã e a Turquia de acordo com o artigo $6^{\circ}$ do Tratado; a integração do sistema de defesa aérea; e a aquisição de armamentos a preços subsidiados pelos russos. O uso da força pela Rússia em apoio às regiões separatistas da Abecásia e Ossétia do Sul em 2008 ainda alimentou a esperança dos armênios de que o mesmo pudesse acontecer no caso de uma tentativa

\footnotetext{
3 "...membership in a strategic alliance necessitates that all alliance members are inherently prohibited against adopting any action that violates the interests of the other alliance members." (NATIONAL SECURITY STRATEGY, 2007).

4 "Serious emphasis will be made on the development of economic cooperation, including the creation of a free trade zone and implementation of programs of joint rational use of natural resources. Specifically, Russia will work for the elaboration of such a status of the Caspian Sea as would enable the littoral states to launch mutually advantageous cooperation in using the region's resources on a fair basis and taking into account the legitimate interests of each other." (THE FOREIGN POLICY, 2000).
} 
de recuperação de Nagorno-Karabakh por parte das tropas azerbaijanas, embora essa região esteja fora dos limites territoriais reconhecidos da Armênia (GERMAN, 2012, p. 1).

A cooperação entre a Rússia e Armênia, seja militar, política ou econômica, supera tanto em número de acordos firmados como em grau de engajamento as relações mantidas pela Rússia com os outros dois países do Cáucaso do Sul. A Armênia, portanto, é o parceiro mais confiável da Rússia na região e a manutenção desta aliança é de extrema importância para a promoção dos seus interesses estratégicos no sul do Cáucaso. O inverso também é verdadeiro. Apesar de ter estado sob o domínio tzarista ou soviético por grande parte dos últimos 200 anos, a Armênia não possui disputas territoriais com a Rússia e não existe histórico de inimizade entre os dois povos (ASATRYAN, 2002, p. 23). Nesses termos, a busca pela independência nos últimos anos da URSS não se traduziu em um sentimento russofóbico, como o que aconteceu na Geórgia. Nas palavras do ex-ministro das relações exteriores da Armênia, Vartan Oskanian: “...apenas na Armênia os sentimentos antissoviéticos não se traduzem em atitudes antirrussas" (OSKANIAN, 2003, tradução livre $^{5}$ ). A esta relação fundamentalmente amistosa, soma-se a necessidade de prover segurança complementar diante da percepção de ameaça proveniente de dois países limítrofes, a Turquia e o Azerbaijão. Ademais, a profunda dependência econômica e energética da Armênia perante a Rússia, potencializada pelos embargos impostos por turcos e azerbaijanos, embora cause desconforto, estreita ainda mais os laços políticos os dois países. Assim, a parceria com a Rússia possui caráter essencial, como deixa claro a Estratégia de Segurança Nacional da República da Armênia:

\begin{abstract}
Embora a Rússia inclua uma parte do Cáucaso, as relações armênio-russas vão muito além do nível regional. A importância do papel da Rússia para a segurança da Armênia, as relações de amizade tradicional entre os dois países, o nível das relações comerciais e econômicas, o papel da Rússia no esforço de mediação Nagorno-Karabakh, bem como a presença de uma comunidade armênia significativa na Rússia, tudo contribui para uma parceria estratégica (NATIONAL SECURITY STRATEGY, 2007, tradução livre $\left.{ }^{6}\right)$
\end{abstract}

Embora a extrema dependência energética e econômica possa ligar um sinal de alerta na relação entre os dois países, as investidas da Rússia para estreitar os laços com o Azerbaijão causam ainda mais preocupação na elite política armênia. Isso demonstra que uma possível deserção da Rússia na aliança causa mais temor do que um hipotético surgimento de um

\footnotetext{
5 "It is in Armenia alone where anti-Soviet sentiments did not translate to anti-Russian attitudes." (OSKANIAN, 2003).

6 "Although Russia includes a part of the Caucasus, ArmenianRussian relations go far beyond the regional level. The importance of Russia's role for the security of Armenia, the traditional friendly links between the two nations, the level of trade and economic relations, Russia's role in the Nagorno Karabakh mediation effort, as well as the presence of a significant Armenian community in Russia, all contribute to a strategic partnership." (NATIONAL SECURITY STRATEGY, 2007)
} 
neoimperialismo russo. A ausência de disputas territoriais, conflitos estratégicos e de animosidade entre os povos também influencia positivamente na manutenção da parceria estratégica.

\section{RELAÇÕES COM O OCIDENTE}

Os interesses estratégicos do Ocidente e, em especial, dos Estados Unidos, no Cáucaso do Sul são perseguidos fundamentalmente através do seu mais poderoso organismo multilateral, a Organização do Tratado do Atlântico Norte (OTAN). Após alçar a posição de Presidente do Conselho Supremo da República Socialista Soviética da Armênia em 1990, Levon Ter-Petrosian visitou Nova lorque, Washington e Los Angeles com o intuito de estreitar os vínculos com a comunidade da diáspora armênia nos EUA. A ajuda financeira e a atuação política organizada da diáspora junto ao Congresso estadunidense se mostraram fundamentais para que o país superasse os difíceis primeiros anos após a independência. Uma das conquistas políticas do lobby armênio foi a inclusão da seção 907 no Freedom Support Act, promulgado pelo Congresso estadunidense em 1992, que proibia o envio de ajuda financeira direta para o Azerbaijão com base nos embargos promovidos pelos azerbaijanos à Armênia e a Nagorno-Karabakh. Esta privação de recursos foi crucial durante o conflito armado entre 1992 e 1994, mais ainda se considerarmos que a ajuda financeira dos EUA à Armênia nesse período representava a quarta maior do mundo e a primeira entre os países recém independentes per capta (MIRZOYAN, 2010, p. 41).

Mesmo com a relevante atuação do lobby da diáspora armênia, os ainda não definidos interesses geoestratégicos estadunidenses para o Cáucaso do Sul impediam uma incursão mais assertiva dos EUA nos assuntos da região. Havia uma aceitação tácita por parte do governo estadunidense de que o destino dos novos Estados sul-caucasianos estava atrelado à Rússia (MIRZOYAN, 2010, p. 142). Em 1994, Vartan Oskanian, o então chefe de assuntos norteamericanos do Ministério das Relações Exteriores da Armênia, resumiu essa posição: "só até uma certa distância que os EUA ou o Ocidente irão. Eles deixaram claro que consideram o nosso destino ligado à Rússia" (OSKANIAN, 1994 apud MIRZOYAN, 2010, p. 142, tradução livre7).

A partir de meados da década de 1990, quando o olhar do Ocidente se voltou para o Cáucaso do Sul, a percepção por parte da Armênia de que os interesses dos EUA passavam a convergir com os do Azerbaijão teve o efeito de aproximar, ao invés de afastar, o país da OTAN. Com a adoção mais incisiva da política de complementariedade a partir da presidência de Robert Kocharian, as relações se intensificaram (KASSAB, 2015, p. 134). Nota-se que a política de

\footnotetext{
7 "There's only a certain distance that the U.S. or the West will go. They have made it clear that they consider our fate tied to Russia's." (OSKANIAN, 1994 apud MIRZOYAN, 2010, p. 142).
} 
complementariedade direcionada às relações com OTAN cumpria não apenas o papel de abrir o leque de opções para a diplomacia armênia, mas também de evitar o protagonismo da narrativa azerbaijana sobre o conflito de Nagorno-Karabakh nas esferas internacionais. Sobretudo no âmbito da OTAN, onde a Turquia, aliada do Azerbaijão, mantém assento (SHIRIYEV, 2015, p. 72).

A busca por uma maior cooperação com a OTAN foi potencializada pela intensificação do engajamento estadunidense no Cáucaso do Sul na esteira da política de "Guerra ao Terror" de George W. Bush, promovida como resposta aos atentados de 11 de setembro de 2001 (CORNELL, 2005a, p. 44). Essa maior cooperação pode ser percebida pela extensa lista de engajamentos quase anuais desde então. No entanto, esse movimento de aproximação tem seus limites. Moscou interpretou a radicalização da política de complementariedade da Armênia como uma guinada ao Ocidente e procurou reforçar sua influência sobre Yerevan (MIRZOYAN, 2010, p. 52; SHIRIYEV, 2015, p. 71). A Rússia também é refratária a continuada expansão da OTAN em direção ao Leste Europeu e ao espaço pós-soviético, o que é percebido como uma ameaça à sua segurança nacional. Após um breve período de comunhão de interesses entre a Rússia e a OTAN com base na luta contra o terrorismo global entre 2001 e 2003 (ZHEBIT, 2009, p. 6), formou-se gradualmente uma distensão entre eles, o que afetou a integração da Armênia com os organismos euroatlânticos. A adesão da Armênia à União Euroasiática, em vez da associação à União Europeia, pode ser entendida como parte deste movimento. Embora não tenha sido acionado oficialmente, o artigo $7^{\circ}$ do Tratado russo-armênio de 1997 oferece aparato legal para o exercício da pressão russa sobre os acordos internacionais da Armênia. Dele consta que:

As Altas Partes Contratantes comprometem-se a abster-se de participar em quaisquer ações ou medidas, e também alianças e blocos, que são dirigidos contra a soberania, independência e integridade territorial da outra Alta Parte Contratante, nem hão de permitir que seu território seja usado com fins de agressão ou outras ações forçosas contra a outra Alta Parte Contratante (A/52/331, 1997, art. 7, tradução livre $\left.{ }^{8}\right)$

Os dirigentes armênios parecem entender o que está em jogo. Em 2006, Robert Kocharian esclareceu que a associação à Organização de Segurança Coletiva e o elevado nível de cooperação técnico-militar com a Rússia "resolvem a tarefa de garantir a segurança do país", e acrescentou que "o conjunto legal que fundamenta as relações russo-armênias na esfera técnicomilitar foi ratificado pelo Parlamento da república" (KOCHARIAN apud ARMENIA NOT, 2006,

\footnotetext{
8 "The High Contracting Parties undertake to refrain from participating in any actions or measures, and also alliances and blocs, which are directed against the sovereignty, independence and territorial integrity of the other High Contracting Party, nor shall they allow their territory to be used for the purposes of aggression or other forcible actions against the other High Contracting Party." (A/52/331, 1997, art. 7).
} 
tradução livre ${ }^{9}$ ). Em uma conferência de imprensa ao completar o primeiro ano de mandato em 2009, Serj Sargsyan afirmou que "é notório que não aspiramos a tornar-nos membros da OTAN, não existe tal item em nossa agenda" (SARGSYAN, 2009, tradução livre ${ }^{10}$ ).

A presença da Turquia como membro da organização é outro elemento que dificulta uma maior integração da Armênia com a OTAN. A posição da Turquia na organização corrobora com a percepção de que a OTAN não seja capaz de prover as garantias de segurança demandadas pela a Armênia. De acordo com Suny (2010, p. 19), tal percepção foi reforçada quando as forças do bloco se esquivaram de prestar auxílio à Geórgia durante a Guerra russo-georgiana de 2008. Perguntado, em uma entrevista concedida ao jornal checo "Lidové Noviny" em 2014, se apoiaria a expansão da OTAN no Cáucaso do Sul, Serj Sargsyan respondeu:

\begin{abstract}
Atualmente, um dos nossos países vizinhos, a Turquia, é membro da OTAN. Isso não acrescenta valor para o nosso sistema de segurança. Embora a Armênia venha fortalecendo as relações de parceria com a OTAN, temos um plano de ação individual; tomamos parte em operações no Kosovo e no Afeganistão, contudo, nunca notamos um membro da OTAN, dentro do formato da Aliança, salientando que a Turquia prejudica significativamente um país parceiro. É paradoxal que tenhamos a nossa participação no sistema de segurança do Atlântico Norte, enquanto a política de um membro OTAN prejudica diretamente o nosso sistema de segurança (SARGSYAN, 2014, tradução livre ${ }^{11}$ )
\end{abstract}

As relações da Armênia com a OTAN não são marcadas pela falta de vontade política por parte dos armênios de uma maior integração, mas estão limitadas pela própria conjuntura política regional e sistêmica. De modo similar ao que acontece nas relações com a Rússia, a Armênia não percebe a OTAN como agente ameaçador, no entanto teme que a organização se incline em favor do Azerbaijão na questão de Nagorno-Karabakh. Esse temor pode ser potencializado caso as relações conturbadas entre a OTAN e a Rússia se deteriorem ou a influência da Turquia sobre as políticas da OTAN seja incrementado.

\footnotetext{
9 "The membership in the Collective Security Treaty Organization (CSTO) and the high level of militarytechnical cooperation with Russia solve the task of ensuring the country's security [...] whole law base of the Armenian-Russian relations in the military-technical sphere has been ratified by the republic's parliament." (ARMENIA NOT, 2006)

10 "... it is well-know that we don't aspire to become a NATO member, there is no such item on our agenda." (SARGSYAN, 2009)

${ }_{11}$ "Currently, only one of our neighboring countries, Turkey is a member of NATO. It is not an added value to our security system. Moreover, although Armenia is strengthening partnership relations with NATO, we have an individual action plan; we take part in operations in Kosovo and Afghanistan, however we have never noticed a NATO member, within the format of the Alliance, pointing out that Turkey significantly harms a partner country. It is paradoxical that we have our input in North Atlantic security system meanwhile, the policy of a NATO member directly harms our security system" (SARGSYAN, 2014).
} 


\section{RELAÇÕES COM O IRÃ}

Mesmo após o advento da República Islâmica em 1979, os armênios representam a maior comunidade não-muçulmana do Irã, tendo seus direitos políticos respeitados e monumentos históricos preservados (KASSAB, 2015, p. 129). Estima-se que a diáspora armênia no Irã atualmente seja composta de 200.000 pessoas, possuindo um papel fundamental nas relações bilaterais entre os dois países (GARFALI et al., 2016, p.15). Os armênios também tratam a cultura iraniana com estima, o ensino do idioma persa é oferecido nas escolas e a Universidade Estatal de Yerevan mantém programas de língua e literatura persas (MIRZOYAN, 2010, p. 109). Essa interseção cultural e a ausência de contendas diplomáticas entre os dois países faz com que o estreitamento das relações com o Irã seja consenso entre todas as forças políticas da Armênia (MIRZOYAN, 2010, p. 108).

Durante o período de existência da URSS, a influência iraniana no Cáucaso do Sul foi extremamente limitada e as relações com o Irã foram conduzidas diretamente por Moscou. A queda do regime soviético abriu espaço para que o Irã retomasse a prática de uma política externa mais ativa na região, que historicamente foi sua área de influência direta. No entanto, o desgaste ocorrido pela guerra com o Iraque e o isolamento político e econômico imposto pelo Ocidente limitaram uma atuação mais assertiva nos assuntos do Cáucaso. Seus objetivos estratégicos imediatos estavam concentrados fundamentalmente na preservação da segurança nacional (RAMEZANZADEH, 1996). A percepção de ameaça advinha da erupção do Conflito de NagornoKarabakh em sua fronteira norte e da possibilidade de expansão dos interesses de potências hostis ao Irã para o Cáucaso do Sul, notadamente a Turquia e os Estados Unidos (GRESH, 2006, p.4).

Entre os países que circundam o Cáucaso do Sul, o Irã é a única república oficialmente islâmica e de maioria xiita. Seria natural que ocorresse um alinhamento com a recém-criada República do Azerbaijão, também de maioria xiita e com profundos laços étnicos com o Irã. Contudo, diante desse cenário, os dirigentes iranianos adotaram uma política externa mais pragmática e condizente com o enfrentamento da ameaça decorrente de um possível fortalecimento do Azerbaijão. Durante a guerra, o Irã praticou uma política de neutralidade que o levou a assumir a posição de mediador do conflito, ainda que não tenha obtido sucesso em assegurar um cessar-fogo permanente (CROISSANT, 1999, p. 79). Vartan Oskanian, ex-ministro das relações exteriores da Armênia, ressaltou em 2003 a importância desse posicionamento estratégico do Irã:

As memórias culturais e históricas compartilhadas entre Irã e Armênia certamente não são maiores que aquelas compartilhadas por Irã e Azerbaijão. Eles compartilham maiores afinidades étnicas e religiosas. A visionária perspectiva geoestratégia do Irã, entretanto, tornou possível para o nosso antigo vizinho 
coexistir pacificamente conosco, Armênia e Azerbaijão, apesar do conflito que nos divide. Isso se apresenta em óbvio contraste com a abordagem míope, inflexível da Turquia (OSKANIAN, 2003, tradução livre ${ }^{12}$ )

Mesmo declarando posição de neutralidade, a premissa de limitar o fortalecimento do Azerbaijão e a expansão dos interesses turcos criavam um ponto de interseção entre os objetivos estratégicos de Teerã e os de Yerevan, já que ambos compartilhavam das mesmas apreensões. Isso levou ao estreitamento das relações entre iranianos e armênios que foi fundamental para aliviar a pressão oriunda do embargo econômico imposto pela Turquia e pelo Azerbaijão à Armênia. Considerando que a guerra civil em curso na Geórgia impedia que as comunicações pelo território georgiano fossem confiáveis, a parceria com a República Islâmica garantia uma rota segura entre a Armênia e o mundo exterior. O constante fornecimento de eletricidade e bens de consumo por parte do Irã, inclusive com o estabelecimento de trocas comerciais com o enclave de NagornoKarabakh (CORNELL, 2005b, p. 309; 318), também foi essencial para a Armênia durante o conflito, e ainda o é atualmente.

Tanto a Armênia quanto o Irã enxergam nessa cooperação uma forma de mitigar o isolamento econômico de ambos. Teerã, em especial, vem sofrendo sanções econômicas dos Estados Unidos e seus aliados ocidentais desde a Revolução Islâmica de 1979. As guerras no Afeganistão e no Iraque, deflagradas pelas potências ocidentais, limitaram ainda mais o espaço de manobra política e comercial do Irã em suas cercanias, fazendo com que a parceria com a Armênia se tornasse ainda mais relevante (GRESH, 2006, p. 6). Não obstante a maior aproximação entre os países seja facilitada pelo mútuo sentimento de isolamento, a "Estratégia de Segurança Nacional" da Armênia deixa claro que esta "imposição de amplas sanções econômicas internacionais contra o Irã também ameaça diretamente a Segurança Nacional da República da Armênia" (NATIONAL SECURITY STRATEGY, 2007, tradução livre ${ }^{13}$ ).

A política de complementariedade da Armênia, contudo, por vezes provoca embaraços. Em 2002, o Embaixador estadunidense em Yerevan, Jonh Ordway, anunciou que os EUA entendem "as dificuldades econômicas da Armênia, mas ao mesmo tempo não apoiamos qualquer investimento na construção do gasoduto através do Irã" (ORDWAY, 2002 apud MIRZOYAN, 2010, p. 128, tradução livre ${ }^{14}$ ). No mesmo ano o Departamento de Estado dos EUA impôs sanções a uma

\footnotetext{
12 "Iran's and Armenia's shared cultural and historical memories are certainly no greater than those shared by Iran and Azerbaijan. They further share ethnic and religious affinities. Iran's visionary, geostrategic outlook however, has made it possible for our ancient neighbor to peacefully coexist with both of us Armenia and Azerbaijan, despite the conflict which divides us. This stands in obvious contrast to Turkey's myopic, inflexible approach." (OSKANIAN, 2003).

13 "The imposition of broad international economic sanctions on Iran would also directly threaten the National Security of the Republic of Armenia," (NATIONAL SECURITY STRATEGY, 2007).

14 "We understand Armenia's economic difficulties, but at the same time we don't support any investment in the construction of the gas pipeline through Iran." (ORDWAY, 2002 apud MIRZOYAN, 2010, p. 128).
} 
empresa armênia acusada de fornecer "equipamentos sensíveis" ao Irã (MIRZOYAN, 2010, p. 128). A despeito do protesto estadunidense, a inauguração do gasoduto que liga o Irã à Armênia em 2007 suscitou o Encarregado de Negócios dos EUA em Yerevan, Anthony Godfrey, a advertir que seu país está "muito preocupado com as crescentes relações com o Irã", embora aprecie "a forma direta com que nos dizem onde estão indo com suas relações" (GODFREY, 2007 apud DANIELYAN, 2007, tradução livre ${ }^{15}$ ). Apesar da pressão americana, a Armênia é resiliente na manutenção de suas relações com o Irã.

Espera-se que se mantido o acordo de regulamentação do programa nuclear iraniano, ao menos por parte dos países europeus, aconteça o levantamento de grande parte das sanções ao país resultando em uma aceleração das relações comerciais do Irã com o Cáucaso do Sul, especialmente no que tange à oportunidade de a região ser utilizada como corredor de trânsito entre o Irã e o mercado consumidor europeu. Nesse sentido, uma maior cooperação energética com a Armênia poderia ser particularmente benéfica para ambas as partes. Ao gás iraniano seria aberta uma nova rota até a Europa, e a Armênia finalmente seria integrada aos projetos energéticos do Cáucaso dos quais tem sido alijada desde a independência, garantindo não apenas sua segurança energética, como também as taxas provenientes do trânsito do gás pelo seu território. No entanto, esse projeto sofre a resistência da Rússia, principal fornecedora de gás para a Europa e detentora do monopólio de distribuição de energia para a Armênia. Outro projeto promissor seria a construção do corredor ferroviário norte-sul, que ligaria a Rússia aos portos iranianos do Golfo Pérsico através dos territórios da Armênia e Geórgia. Mas a instabilidade das fronteiras russogeorgianas, notadamente após a guerra de 2008, e a recente reaproximação de Moscou e Teerã com Baku, sugerem que esse corredor ferroviário tenha seu trajeto alterado para o território do Azerbaijão (FALYAKHOV, 2016).

Não se verifica nenhum aspecto político ou econômico que aponte para uma deterioração das relações entre Armênia e Irã. Uma possível alteração desse cenário pode ocorrer no caso de uma ação mais incisiva da Rússia para evitar uma potencial competição com o Irã pelo mercado energético europeu ou com a renovação das hostilidades com o Ocidente após o recente cancelamento unilateral do acordo nuclear por parte dos EUA. Ainda assim, em ambos os casos, essas são ameaças indiretas que não alteram a percepção da Armênia com relação ao Irã.

\footnotetext{
15 "We are very concerned about the increasing relations with Iran." - "We do appreciate the transparent way in which the government of Armenia conducts its energy relations with Iran, and we appreciate the straightforward way that they tell us where they are going with their relations." (DANIELYAN, 2007).
} 


\section{RELAÇÕES COM A TURQUIA}

A história das relações entre Armênia e Turquia é marcada pelo genocídio impetrado pelo Império Otomano contra a população armênia no início do século XX. A memória do genocídio e a luta para que ele seja reconhecido pela comunidade internacional se tornariam elementos fundamentais para a formação da moderna identidade armênia. Ainda assim, a Turquia foi um dos primeiros países a reconhecer a independência da Armênia após o colapso soviético, embora tenha enfatizado que o reconhecimento se estendia apenas às fronteiras já delimitadas. Ancara, entretanto, se recusou a estabelecer relações diplomáticas sob a justificativa de que a normalização só seria possível em caso de renúncia à busca do reconhecimento internacional do genocídio e da desistência de antigas reivindicações por territórios.

Outro fator que norteia as relações entre os países é a questão de Nagorno-Karabakh. $A$ priori, os turcos escolheram não tomar partido declarado no conflito (CORNELL, 1997, p. 13). No entanto, as conquistas militares das tropas armênias e as baixas sofridas pelos azerbaijanos influenciaram a opinião pública na Turquia e a oposição política nacionalista, que passaram a pedir por um maior envolvimento do país em apoio ao Azerbaijão, cuja população compartilha da mesma origem étnica túrquica. A pressão resultou em declarações como a do ministro de relações exteriores Hikmet Çetin que, em discurso ao Parlamento em 1992, assegurou que a Turquia "em solidariedade com o fraterno Azerbaijão nunca permitirá qualquer mudança no status legal do enclave azerbaijano de Nagorno-Karabakh", e acrescentou que "a Armênia será responsável pelas consequências de sua agressão" (ÇETIN, 1992 apud MIRZOYAN, 2010, p. 68, tradução livre ${ }^{16}$ ). Em 1993 tropas turcas foram posicionas nas fronteiras, que foram novamente fechadas em retaliação à ocupação armênia do distrito azerbaijano de Kelbakar. Também foi proibido o trânsito de ajuda humanitária para a Armênia pelo território turco e negado o espaço aéreo aos voos de origem ou com destino à Armênia. Apesar dessas medidas, a Turquia não ofereceu ajuda militar direta ao Azerbaijão durante a guerra.

A hostilidade demonstrada pela Turquia contrastava com a aspiração do governo armênio de restabelecer as relações com o país vizinho. Em uma entrevista ao jornal "Turkiye" em 1992, Levon Ter-Petrosian declarou o desejo de "cooperação com a Turquia em todas as esferas" e de que "o estabelecimento de laços econômicos sirva de base para a construção de relações amistosas" (TER-PETROSIAN, 1992 apud OSKANIAN-GUL MEETING, 2013, tradução livre ${ }^{17}$ ). Mesmo com a pressão de parte da opinião pública e, fundamentalmente, da diáspora armênia, que

\footnotetext{
16 "... in solidarity with brotherly Azerbaijan will never permit any changes in the Azeri enclave of NagornoKarabakh's judicial status." (MIRZOYAN, 2010, p. 68).

17 "We aspire to cooperation with Turkey in all spheres. We want the establishment of economic ties to serve a basis for settlement of friendly relations." (OSKANIAN-GUL MEETING, 2013).
} 
em sua maioria continua considerando essas questões inegociáveis, o reconhecimento do genocídio e a reivindicação de territórios ancestrais deixaram de ser pré-condições para qualquer acordo. A rejeição da oposição interna a qualquer tipo de conciliação sobre o status de NagornoKarabakh e o intenso sentimento antiturco que o próprio movimento nacionalista ajudou a disseminar foram profundos entraves para a estratégia de reaproximação.

$\mathrm{Na}$ Turquia também havia resistência a uma reaproximação. Ela pode ser compreendida pelo receio de que uma aproximação com Yerevan possa causar ressentimentos no Azerbaijão, seu principal aliado no Cáucaso. Existe a percepção na Armênia de que as hostilidades promovidas pela Turquia são fundamentalmente derivadas da parceria estratégica que esta possui com o Azerbaijão (CORNELL, 2005b, p. 294). A influência que Baku exerce sobre a política externa de Ancara pôde ser percebida novamente, anos mais tarde, quando uma nova tentativa de aproximação entre Turquia e Armênia foi posta em pauta no que ficou conhecida como "diplomacia do futebol". Em setembro de 2008, o Presidente turco aceitou um convite de seu homólogo armênio, Serj Sargsyan, para assistir uma partida de futebol entre as seleções dos dois países em Yerevan. Essa foi a mais relevante demonstração pública de aproximação entre as duas partes que já havia dado sinais de progresso nos anos anteriores com o estabelecimento da Comissão TurcoArmênia de Reconciliação em 2001, a suspensão das restrições de visto para cidadãos armênios em 2002 e a restauração por parte do governo turco da histórica igreja armênia de Akhtamar, na província turca de Van, em 2007 (GARFALI et al., 2016, p. 12). A “diplomacia do futebol” resultou na assinatura de protocolos que, inter alia, garantiam a reabertura das fronteiras e 0 restabelecimento de relações diplomáticas entre os dois países.

O reengajamento entre Armênia e Turquia gerou consternação no Azerbaijão. O Presidente azerbaijano Ilham Aliyev ameaçou encontrar destinos alternativos à Turquia para a exportação de seu gás natural (AZERBAIJAN THREATENS, 2009). Aliyev já havia anteriormente condicionado a realização do projeto do gasoduto que liga Baku à cidade portuária turca de Ceyhan à manutenção do embargo turco à Armênia (CORNELL, 2005b, p. 294). Ademais, as objeções de Baku eram compartilhadas com a opinião pública turca, amplamente desfavorável ao acordo (SAMMUT, 2015, p. 48). Em resposta ao descontentamento de Baku e de sua própria opinião pública, o então Primeiro-Ministro turco, Recep Erdogan, acentuou que a normalização das relações com a Armênia e a solução da questão de Nagorno-Karabakh são dois processos paralelos e que a Turquia não abriria as fronteiras com a Armênia antes que esta retirasse suas tropas do território azerbaijano. A imposição de condições para a normatização das relações por parte do governo turco acabou por minar o processo, nem o Parlamento turco, nem o armênio seguiram com a ratificação dos protocolos assinados. Foi um grande golpe nas intenções da Armênia em ter reabertas suas 
fronteiras com a Turquia e, consequentemente, assegurar uma rota segura de acesso aos mercados europeus.

Mesmo na ausência de relações diplomáticas e com as fronteiras fechadas, o comércio entre Armênia e Turquia é significativo. Desde a metade da década passada, as importações armênias provenientes da Turquia estão em níveis similares, e por vezes superiores, àquelas do Irã, com quem a Armênia nutre boas relações. O transporte de mercadorias é realizado através do território da Geórgia, que possui acordos de livre comércio com ambos os vizinhos. Já o fluxo comercial no sentido inverso, embora existente, representa montante insignificante. Isso se dá em função das restrições mais rígidas impostas pelos turcos aos produtos armênios, mas, sobretudo, pela incapacidade da economia armênia em produzir bens requisitados pelo país vizinho (THE UNION, p. 2).

Apesar das maneiras encontradas para contorná-lo, o embargo econômico imposto pela Turquia em solidariedade ao Azerbaijão é tido pela Armênia como uma ação ofensiva à sua segurança nacional. A "Doutrina Militar da República da Armênia”, promulgada em 2007, inclui na seção onde enumera as ameaças externas enfrentadas pelo país:

O estabelecimento, o fortalecimento e a ampliação de alianças contra a República da Armênia, especialmente a aliança estratégica entre a República da Turquia e a República do Azerbaijão, suas atividades destinadas a manter o bloqueio da República da Armênia, que são vistos como uso da força (MILITARY DOCTRINE, 2007, tradução livre ${ }^{18}$ ).

Já uma ameaça militar parece mais distante. Desde a mobilização das tropas turcas nas fronteiras durante a guerra de Nagorno-Karabakh, não houve nenhum evento concreto que incitasse temor aos armênios. Mas a posição geográfica do país e a percepção de que a Turquia passou a ser parte diretamente interessada no conflito de Nagorno-Karabakh, obriga que os armênios não negligenciem essa questão. Logo após uma retomada dos confrontos ter ocorrido em abril de 2016 na linha de contato entre tropas azerbaijanas e armênias em Nagorno-Karabakh, o Presidente turco Recep Erdogan telefonou para o Presidente Ilham Aliyev prestando sua solidariedade e afirmou estar rezando para que "nossos irmãos azeris prevaleçam" (ERDOGAN, 2016 apud INTERNATIONAL CRISIS GROUP, 2016, p. 9, tradução livre ${ }^{19}$ ). O acordo militar firmado entre Turquia e Azerbaijão em 2010, que prevê auxílio mútuo em caso de agressão a ambas as partes (TURKISH MILITARY, 2015), corrobora ainda mais com essa percepção. Nesse contexto,

\footnotetext{
18 "the establishment, strengthening and expansion of alliances against the Republic of Armenia, especially the strategic alliance between the Republic of Turkey and the Republic of Azerbaijan, their activities aimed at maintaining the blockade of the Republic of Armenia, which are viewed as use of force" (MILITARY DOCTRINE, 2007).

19 “...our Azerbaijani brothers will prevail ...” (INTERNATIONAL CRISIS GROUP, 2016, p. 9).
} 
as tropas russas estacionadas na Armênia continuam indispensáveis para manter o status de dissuasão vis-à-vis a Turquia. Como apontou em uma conferência promovida pela OTAN em 2005 o então ministro da defesa, e agora Presidente, Serj Sargsyan: "[as tropas russas] são um componente da nossa segurança nacional e sua presença é contingente às relações da Armênia com a Turquia, que ainda nos é hostil” (SARGSYAN, 2005 apud SUNY, 2010, p. 18, tradução livre ${ }^{20}$ ).

É manifesta a influência que o passado conturbado no desenrolar das relações entre armênios e turcos, notadamente no que tange ao direcionamento da opinião popular nos dois países. Mas os dirigentes armênios vêm procurando se desvencilhar dessa armadilha histórica e promover uma reaproximação com a Turquia, o que atenderia aos interesses estratégicos do país. Essa busca por reconciliação sugere o entendimento de que a ameaça oferecida pelos turcos pode ser ao menos minimizada através da diplomacia. No entanto, a recusa da Turquia em retomar as relações e suspender o embargo sem a imposição de condições e a insistência em manter uma política externa associada aos interesses do Azerbaijão não contribuem para a redução do nível de ameaça percebido pela Armênia, que permanece alto.

\section{CONSIDERAÇÕES GERAIS E CONCLUSÕES}

Conclui-se que duas são as suas preocupações mais recorrentes desde a proclamação de sua independência. A primeira diz respeito à conservação e à ampliação das rotas que conectam o país ao restante do mundo de modo a evitar o isolamento físico, a interrupção do fornecimento de energia e o alijamento da Armênia dos benefícios do comércio e dos grandes projetos de infraestrutura regionais. A segunda é com a proteção da integridade do território nacional e, por extensão, o da República de Nagorno-Karabakh. Essas duas preocupações estão, não coincidentemente, associadas ao grau de ameaça percebida pela Armênia em relação à Turquia e ao Azerbaijão. Neste cenário, justifica-se a constatação de que a Rússia foi, durante os anos, alçada ao posto de aliada fundamental justamente por oferecer as garantias necessárias para suprir as demandas de segurança da Armênia. Percebe-se, ademais, que mesmo diante da alternância de poder e as diversas tentativas de implementar a complementaridade a dependência da Rússia persiste.

Entende-se que outros alinhamentos poderiam, em hipótese, atender os objetivos estratégicos do país por caminhos diferentes. É previsto pela literatura que teoriza acerca da

20 " "...are a component of our national security and their presence is contingent on Armenia's relations with Turkey which is still hostile to us". (SUNY, 2010, p. 18). 
formação de alianças a possibilidade de o alinhamento de um país se dar com sua própria fonte de ameaça (bandwagon), caso esta opção atenue as pressões sobre sua segurança nacional (WALT, 1990, p.17). No entanto, como detalhado a seguir, dada as particularidades do caso da Armênia, a busca por parceiros confiáveis se restou limitada a uma opção.

A Turquia, em conjunção ao Azerbaijão, apresenta uma ameaça à Armênia, o que implicaria em um possível alinhamento em bandwagon. No entanto, e não obstante os empecilhos causados pelo passado turbulento, a hipótese de se aliar à Turquia apenas atenderia a uma das duas maiores consternações da segurança nacional armênia. $O$ isolamento do país seria em grande parte resolvido e os novos mercados que se abririam poderiam compensar a provável diminuição da atividade comercial com a Rússia. Por outro lado, a Turquia não é capaz de assegurar a segurança energética da Armênia, já que ela própria é dependente dos recursos do Azerbaijão e, fundamentalmente da Rússia. Ademais, o principal impeditivo de uma aliança com a Turquia está relacionado com o segundo pilar da segurança nacional armênia, a manutenção da integridade territorial do país e, sobretudo, a independência de Nagorno-Karabakh. A aliança entre turcos e azerbaijanos é calcada não apenas na afinidade étnica, mas também nos interesses comerciais e estratégicos das duas partes. Essa parceria se mantém sólida desde a desintegração soviética, ao ponto de não terem sido raras as vezes em que os interesses do Azerbaijão produziram eco na sociedade e na política turca. Diante desse cenário, uma aliança entre armênios e turcos, mesmo que assimétrica e desfavorável aos primeiros, só seria possível caso as demandas azerbaijanas fossem acomodadas, das quais a reintegração de Nagorno-Karabakh aparece como prioridade. Assim, a hipótese de um alinhamento com Turquia não garantiria à Armênia ganhos concretos em Segurança, restando inviável.

Com o Irã a Armênia mantém relações estáveis e de cooperação, mas a formalização de uma aliança entre os dois não atenderia aos interesses de nenhuma das partes. O Irã sofre há mais de três décadas com sanções que limitam seriamente o seu desenvolvimento econômico, além de possuir uma considerável minoria azeri que poderia se opor a um maior envolvimento de seu país em uma aliança que estaria em oposição aos interesses do Azerbaijão. As pressões vindas do Ocidente e do seu conturbado entorno geográfico também fazem com que a política externa iraniana se torne mais cautelosa na sua estratégia de engajamento no Cáucaso do Sul. Uma aliança formal com a Armênia resultaria na adesão a compromissos que iriam de encontro com a fundamental preocupação iraniana com a própria segurança nacional. Por sua vez, uma aliança com o Irã faria com que a Armênia perdesse a confiança do Ocidente o que acarretaria, no melhor dos cenários, o agravamento do isolamento do país.

Nos primeiros anos após a independência e durante a guerra aberta por Nagorno-Karabakh, a OTAN e as potências ocidentais mantiveram-se afastadas de um maior envolvimento no Cáucaso 
do Sul. Portanto, em um primeiro momento, o alinhamento com a OTAN não era uma opção para a Armênia. Os interesses na exploração e distribuição dos recursos energéticos do Mar Cáspio, somados à política de confrontação com a Rússia, tornaram mais consistentes as atividades da OTAN na região. No entanto, na perspectiva armênia, o propósito de balancear as ameaças vindas da Turquia e Azerbaijão através de uma aliança com a OTAN estaria em desalinho com o própria estrutura e objetivos da organização. O primeiro entrave está no fato de a Turquia ser um membro da OTAN, condicionando a adesão da Armênia à normalização das relações entre os dois países. O segundo deriva da ausência de recursos energéticos significativos na Armênia, em justaposição à abundância no Azerbaijão. Sendo os interesses econômicos um dos maiores propulsores da atividade da OTAN na região, restariam poucas garantias à Armênia de que os esforços em direção a um alinhamento com o Ocidente resultariam em vantagens vis-à-vis o país vizinho. Mais além, a adoção de uma orientação estritamente pró-Ocidente alienaria a Rússia e o Irã, que são o maior parceiro comercial e militar e essencial via de ligação com o mundo exterior, respectivamente.

A aliança com a Rússia, portanto, foi a opção seguida pela Armênia, ainda que essa parceria não seja isenta de contestações. A superdependência econômica, militar e energética da Armênia perante os russos reduz a capacidade do Estado em gerir seus próprios interesses e relativiza a soberania do país. Contudo, o provimento de segurança para a defesa do território nacional é atendido por Moscou de forma confiável. As tropas e bases militares russas em território armênio, herdadas da época soviética, foram cruciais como elementos dissuasórios de uma invasão estrangeira durante a guerra por Karabakh, período no qual a Rússia foi o único ator disposto a prover auxílio à defesa da Armênia. Atualmente o cenário permanece sem muitas alterações, a Rússia continua sendo o único aliado disponível e forças da OTSC, fundamentalmente russas, garantem a segurança das fronteiras da Armênia. Esta disposição libera os recursos próprios da Armênia para serem usados na defesa de Nagorno-Karabakh. A aquisição de armamentos a preços subsidiados é outro fator que garante que a superioridade econômica do Azerbaijão não seja traduzida em superioridade militar flagrante. Na perspectiva russa, a parceria com a Armênia garante o único aliado confiável em uma região que por séculos esteve sob seu domínio. Logo, é possível dizer que a aliança russo-armênia é menos uma opção do que uma imposição da conjuntura real.

* Artigo recebido em 11 de setembro de 2019, aprovado em 16 de novembro de 2019. 


\section{REFERENCIAS}

DOCUMENTOS:

A/52/331 (DOCUMENTO DA ONU). Treaty between the Russian Federation and the Republic of Armenia on friendship, cooperation and mutual assistance. 1997. Disponível em: <http://www.un.org/documents/>. Acesso em: set. 2016.

THE FOREIGN POLICY Concept of the Russian Federation. Federação Russa. 2000. Disponível em: $<$ http://archive.mid.ru/>. Acesso em: set. 2016.

INTERVIEW of president serzh sargsyan to the czech "lidové noviny" (national news). 2014. Disponível em: http://www.president.am/en/interviews-and-pressconferences/item/2014/01/30/Interview-of-President-Serzh-Sargsyan-durin-state-visit-to-CzechRepublic/. Acesso em: nov. 2016.

MILITARY DOCTRINE of the Republic of Armenia. República da Armênia. 2007b. Disponível em: $\leq$ http://www.mil.am/>. Acesso em: set. 2016.

NATIONAL SECURITY STRATEGY. República da Armênia. 2007. Disponível em: <www.mfa.am>. Acesso em: set. 2016.

OSKANIAN, Vartan. Speech by His Excellency Vartan Oskanian Minister of Foreign Affairs, Republic of Armenia at the Pro-Armenia Conference Armenia in the 21st Century. 2003. Disponível em: <http://www.mfa.am/en/>. Acesso em: nov. 2016.

PRESS CONFERENCE Of President Serzh Sargsyan Marking His One Year In Office. 2009. Disponível em: http://www.president.am/en/interviews-and-pressconferences/item/2009/04/10/news-23/. Acesso em: nov. 2016.

FONTES DE MÍDIA ONLINE:

ARMENIA NOT to join NATO, EU: president. XINHUA. Abril de 2006. Disponível em: http://en.people.cn/200604/24/print20060424_260758.html. Acesso em: nov. 2019.

AZERBAIJAN THREATENS Turkey Over Armenia Agreement. RFE/RL. Outubro de 2009. Disponível em: www.rferl.org/a/Azerbaijan_Threatens_Turkey_Over_Armenia_Agreement/1857198.html. Acesso em: nov. 2019.

DANIELYAN, Emil. US Concerned by Armenia's Energy Ties with Iran. EURASIANET. Junho de 2007. Disponível em: https://eurasianet.org/us-concerned-by-armenias-energy-ties-with-iran. Acesso em: nov. 2019.

FALYAKHOV, Rustem. Russia, Iran \& Azerbaijan to complete transport corridor. RBTH. Agosto de 2016. Disponível em: https://in.rbth.com/world/2016/08/10/russia-iran-azerbaijan-to-completetransport-corridor_619673. Acesso em: nov. 2019. 
KUCERA, Joshua. Azerbaijan Gets 85 Percent of Its Weapons from Russia. EURASIANET. Março de 2015. Disponível em: http://www.eurasianet.org/node/72581. Acesso em: nov. 2019.

OSKANIAN-GUL MEETING: will the long-lasting timeout be interrupted? TABDC. Maio de 2013. Disponível em: http://www.tabdc.org/oskanian-gul-meeting-will-the-long-lasting-timeout-beinterrupted-5/. Acesso em: nov. 2019.

TURKISH MILITARY Cooperation Prompts Russian Military Moves in the Caucasus. STRATFOR. Julho de 2015.2 Disponível em: https://article.wn.com/view/2015/07/13/Turkish_Military_Cooperation_Prompts_Russian_Military_ Moves_/. Acesso em: dez. 2019.

\section{BIBLIOGRAFIA:}

ASATRYAN, Garnik S. Armenia and security issues in the South Caucasus. The Quarterly Journal, v. 3, p. 21-30, 2002.

BUENO DE MESQUITA, Bueno. Foreign Policy Analysis and Rational Choice Models. International Studies Association Compendium Project Paper, 2009.

CORNELL, Svante. Security Threats and Challenges in the Caucasus after 9/11. In: COHEN, Ariel (org.), Eurasia in Balance: The US and the Regional Power Shift, p. 45-68, Gower Publishing, 2005a.

. Small nations and great powers: a study of ethnopolitical conflict in the Caucasus. London: Routledge, 2005b.

. Undeclared War: The Nagorno-Karabakh Conflict Reconsidered. Journal of South Asian and Middle Eastern Studies, v. 20, n. 4, 1997.

CROISSANT, Michael P.; ARAS, Bülent. Oil and geopolitics in the Caspian Sea region. Westport: Greenwood Publishing Group, 1999.

GARFALI, Orhan; ANAPIOSYAN, Arevik; ÖSTARZU, Mehmmet; CHAPICHADZE, Khatuna. The Role of Global and Regional Actors in the South Caucasus. Caucasus Edition -Journal of Conflict Transformation, 2016.

GERMAN, Tracey. The Nagorno-Karabakh Conflict between Azerbaijan and Armenia: Security Issues in the Caucasus. Journal of Muslim Minority Affairs, v. 32, n. 2, p. 216-229, 2012.

GRESH, Geoffrey. Coddling the Caucasus: Iran's strategic relationship with Azerbaijan and Armenia. Caucasian Review of International Affairs, v. 1, n. 1, p. 1-13, 2006.

INTERNATIONAL CRISIS GROUP. Nagorno-Karabakh: New Opening, or More Peril?. Crisis Group Europe Report, n 239, Baku/Yerevan/Vienna/Brussels, 2016.

KASSAB, Hanna Samir. Weak States in International Relations Theory: The Cases of Armenia, St. Kitts and Nevis, Lebanon, and Cambodia. New York, Palgrave Macmillan, 2015.

MIRZOYAN, Alla. Armenia, the regional powers, and the West: between history and geopolitics. New York: Palgrave Macmillan, 2010. 
RAMEZANZADEH, Abdollah. Iran's Role as Mediator in the Nagorno-Karabakh Crisis. Disponível em: http://poli.vub.ac.be/publi/ContBorders/eng/ch0701.htm. Acesso em: out. 2016.

SAMMUT, Dennis. Armenia-Stuck between a rock and a hard place. In: The South Caucasus Between integration and fragmentation. Brussels: European Policy Centre, p. 45-52, 2015.

SHIRIYEV, Zaur. NATO's South Caucasus paradigm: beyond 2014. In: The South Caucasus Between integration and fragmentation. Brussels: European Policy Centre, p. 67-76, 2015.

SUNY, Ronald. The pawn of great powers: The East-West competition for Caucasia. Journal of Eurasian Studies, v. 1, n. 1, p. 10-25, 2010.

THE UNION of manufacturers and businessmen of Armenia. Impediments to Direct Trade between Turkey and Armenia. Disponível em: http://umba.am/pics/direct_trade_report.pdf. Acesso em: nov/2019.

WALT, Stephen M. The origins of alliances. Ithaca: Cornell University Press, 1990.

WALTZ, Kenneth. Theory of International Politics. New York: McGrawHill, 1979.

ZHEBIT, Alexander. A política externa russa pós-Guerra Fria: um intróito à mudança. Cadernos ADENAUER (São Paulo), v. 10, p. 93-110, 2009. 